\title{
Cloud macroscopic organization: order emerging from randomness
}

\author{
T. Yuan \\ Joint Center for Environmental Technology, UMBC, Baltimore, MD, USA \\ Laboratory for Atmosphere, NASA Goddard Space Flight Center, Greenbelt, MD, USA \\ Received: 28 December 2010 - Published in Atmos. Chem. Phys. Discuss.: 17 January 2011 \\ Revised: 22 June 2011 - Accepted: 5 July 2011 - Published: 1 August 2011
}

\begin{abstract}
Clouds play a central role in many aspects of the climate system and their forms and shapes are remarkably diverse. Appropriate representation of clouds in climate models is a major challenge because cloud processes span at least eight orders of magnitude in spatial scales. Here we show that there exists order in cloud size distribution of low-level clouds, and that it follows a power-law distribution with exponent $\gamma$ close to 2. $\gamma$ is insensitive to yearly variations in environmental conditions, but has regional variations and landocean contrasts. More importantly, we demonstrate this selforganizing behavior of clouds emerges naturally from a complex network model with simple, physical organizing principles: random clumping and merging. We also demonstrate symmetry between clear and cloudy skies in terms of macroscopic organization because of similar fundamental underlying organizing principles. The order in the apparently complex cloud-clear field thus has its root in random local interactions. Studying cloud organization with complex network models is an attractive new approach that has wide applications in climate science. We also propose a concept of cloud statistic mechanics approach. This approach is fully complementary to deterministic models, and the two approaches provide a powerful framework to meet the challenge of representing clouds in our climate models when working in tandem.
\end{abstract}

\section{Introduction}

Low-level warm clouds exert a strong negative radiative effect on the climate system by reflecting a large fraction of incoming solar radiation back to space while emitting a similar amount of longwave radiation as the Earth's surface

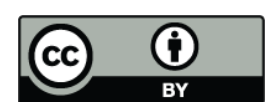

Correspondence to: T. Yuan

(tianle.yuan@nasa.gov)
(Ramanathan et al., 1989; Hartmann and Doelling, 1991). These warm clouds appear in widely different and seemingly chaotic forms and sizes. For instance, while stratocumulus cloud sheets over oceans can have a relatively homogeneous appearance at spatial scales of $\sim 100 \mathrm{~km}$, the inhomogeneity of trade cumulus and fair weather cumulus clouds can be easily appreciated at scales as small as $10 \mathrm{~m}$ (Wielicki and Welch, 1986; Cahalan and Joseph, 1989; Zhao and Di Girolamo, 2007). The appearance, or macroscopic organization, of these clouds is regulated by a set of complex and interacting micro- and macro- scale processes (Klein and Hartmann, 1993; Stevens and Feingold, 2009) operating at spatial scales ranging from Kolmogorov scale $\sim 1 \mathrm{~mm}$ to typical meteorological mesoscale $\sim 100 \mathrm{~km}$, a span of eight orders of magnitudes. The large spatial scale range is an insurmountable challenge for deterministic physical cloud models (Siebesma and Jonker, 2000; Stevens, 2005) and will be in the foreseeable future. Yet, these clouds are at the heart of uncertainties related to future climate simulations (Bony et al., 2006). We have to rely on observational and modeling techniques to derive the most essential part of cloud variability and its relationship with the environment in order to appropriately account for them in climate models.

\section{Data and method}

Here we use the MODerate resolution Imaging and Spectroradiometer (MODIS) cloud product to look at cloud macroscopic organization. The MODIS cloud product provides a $1-\mathrm{km}$ resolution cloud mask. Cloud thermodynamic phase (i.e., a determination of whether a cloudy pixel is liquid, ice, or mixed) and retrieval quality assurance data are also available at the same spatial resolution (Platnick et al., 2003). Based on MODIS cloud mask data, we define a cloud as a patch of cloudy pixels connected through four-neighbor connectivity (i.e., diagonal neighbors are ignored). Results in the

Published by Copernicus Publications on behalf of the European Geosciences Union. 
paper are not affected by the choice of four-neighbor or eightneighbor connectivity. The size of a cloud is simply taken as the number of pixels a cloud contains. For each level-2 granule (approximately $2340 \times 2030 \mathrm{~km}$ ), only "confidently cloudy" pixels are retained based on the cloud mask and quality assurance flags (for details see Platnick et al., 2003). We then scan this filtered cloud mask field and find individual clouds as defined above. Since in this study we are only interested in warm liquid clouds, any cloud that contains a non-liquid (mixed or ice phased) pixel is not included in our sampling database. Finally, we are only interested in clouds that have relatively larger size, and any cloud whose diameter is smaller than $3 \mathrm{~km}$ is removed. This is recognizing first that data at MODIS resolution $(1 \mathrm{~km})$ would introduce large uncertainties when used to study clouds at smaller scales (Wielicki and Welch, 1986; Zhao and Di Girolamo, 2007). It is also because we are interested in cloud organizations at scales larger than the typical break scale $(\sim 1 \mathrm{~km})$ observed for trade cumuli (Cahalan and Joseph, 1989), even though small-scale statistics are also rich and important (Neggers et al., 2003; Koren et al., 2008; Jiang et al., 2009).

\section{Results}

Previous studies have shown that despite the highly inhomogeneous appearance of trade cumulus and fair-weather cumulus clouds, there exists order in a statistical sense for small (less than $\sim 1 \mathrm{~km}$ in diameter) clouds (Cahalan and Joseph, 1989; Benner and Curry, 1998). In Fig. 1 normalized number frequency is plotted against cloud size on a log-log scale for a trade-cumulus dominated region $\left[5^{\circ} \mathrm{N} \sim 30^{\circ} \mathrm{N}\right.$, $\left.170^{\circ} \mathrm{W} \sim 155^{\circ} \mathrm{W}\right]$. The normalized number frequency is defined as $P_{k}=N_{k} /\left(N S_{k}\right)$, where $\mathrm{N}_{k}$ is the number of clouds within the $k_{\text {th }}$ size bin, $N$ is the total number of clouds in a sample, and $S_{k}$ is the size of $k_{\text {th }}$ bin. The different curves are based on July data of different years (2003-2010). The number of clouds sampled for each curve is on the order of 100000 . We find that similar to small clouds, the cloud size distribution of larger warm clouds studied here follows a power-law: $P_{k}=C K^{-\gamma}$. The scale-free power law relationship between number frequency and cloud size holds for all the years (2003-2010) analyzed. The multi-year mean of the exponent $\gamma$ for the power law relationship is $1.95 \pm 0.036$, with 0.036 being the standard deviation. Correlation coefficient between $\log \left(P_{k}\right)$ and $\log (K)$ is always greater than 0.99 (same for other plots), indicating a good fit to the powerlaw.

Interestingly, the observed $\gamma$ is nearly identical to estimates for warm oceanic convective clouds that are smaller than $\sim 1 \mathrm{~km}$ (Kuo et al., 1993; Benner and Curry, 1998; Zhao and Di Girolamo, 2007). We postulate that the scale-free behavior has no break between scales of $O(10 \mathrm{~m})$ and of $O$ $(100 \mathrm{~km})$, four orders of magnitude difference. The break reported in previous studies is probably due to insufficient sam- pling of larger clouds (recall that $P_{k} \sim K^{-\gamma}$ ) because those studies used only a few cloudy scenes with each covering an area $\sim 10000 \mathrm{~km}^{2}$ or less (Zhao and Di Girolamo, 2007). In comparison, we used about 200 cloudy scenes every year with each covering $\sim 1000000 \mathrm{~km}^{2}$, a roughly 4 orders of magnitude increase in total sampling for larger clouds. More importantly, the ratio between the size of a scene and the cloud size is too small for previous studies that used high resolution data, but small granule size. As a result, larger clouds in previous studies are exceedingly less likely to be sampled, and even if they are present in a scene, it is very likely that they are on the edge and therefore not completely sampled, leading to a low bias in their observed frequency of occurrence.

Another important feature is that the power law exponent $\gamma$ is rather constant during the eight-year period. This is unexpected because, despite the generally homogeneous trade wind circulation within a particular month, there exists strong interannual variation. For example, the mean cloud fraction reported by MODIS fluctuates by more than $30 \%$ over these years. The invariant behavior indicates the warm cloud organization is much less sensitive to environmental conditions than the bulk cloud fraction. Observing the scalefree behavior and the insensitivity of the exponent to largescale conditions, we hypothesize that these warm trade cumulus clouds have robust intrinsic statistical organization, i.e., they are self-organized. The notion of self-organization generally refers to the property of a system where emerging order or structure appears on its own without any external involvement. In other words, in self-organizing systems, the system-wide, emerging order or structure results automatically from micro-scale interactions among internal components of the system.

This self-organizing behavior is supported by our analyses from other regions as well as previous studies (Cahalan and Joseph, 1989; Benner and Curry, 1998; Kuo et al., 1993; Benner and Curry, 1998; Zhao and Di Girolamo, 2007). We analyzed data for trade cumuli over the Caribbean Ocean and Subtropical South Pacific (not shown here) and fair-weather cumuli over the west Amazon Basin (Fig. 3a). Cloud organization at these locations have similar characteristics: the cloud size distribution follows a power law $\left(P_{k}^{\prime} \sim K^{-\gamma^{\prime}}\right.$, $\left.P_{k}^{\prime}=P_{k *} S_{k}\right)$ and the exponent $\gamma^{\prime}\left(\gamma^{\prime}=\gamma-1\right)$ is insensitive to yearly variations in large-scale condition. However, $\gamma^{\prime}$ does have regional differences; for instance, it is 1.1 for trade wind cumulus over the Caribbean ocean and 0.83 (Terra) 0.91 (Aqua) for fair-weather cumulus over the Amazon. Furthermore, the diurnal variation of the cloud self-organization has interesting land-ocean contrast: $\gamma^{\prime}$ has larger variation over land than over ocean (Fig. 1); and while values in the early afternoon (Aqua MODIS) are consistently smaller than those in the mid-morning (Terra MODIS) over ocean, suggesting an increase in overall cloud size, it is the opposite over land (here we show data from over the Amazon during the month 

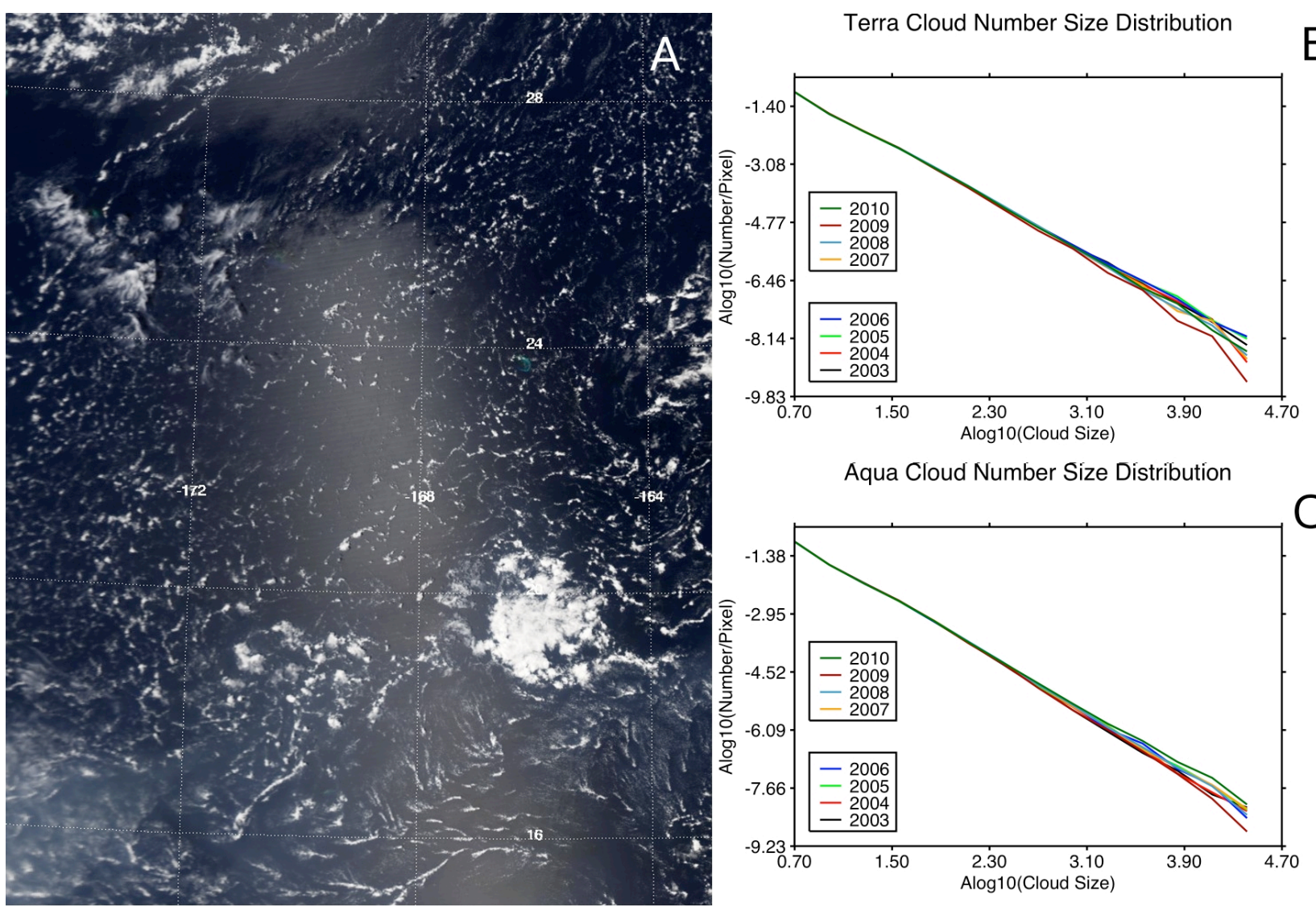

Aqua Cloud Number Size Distribution

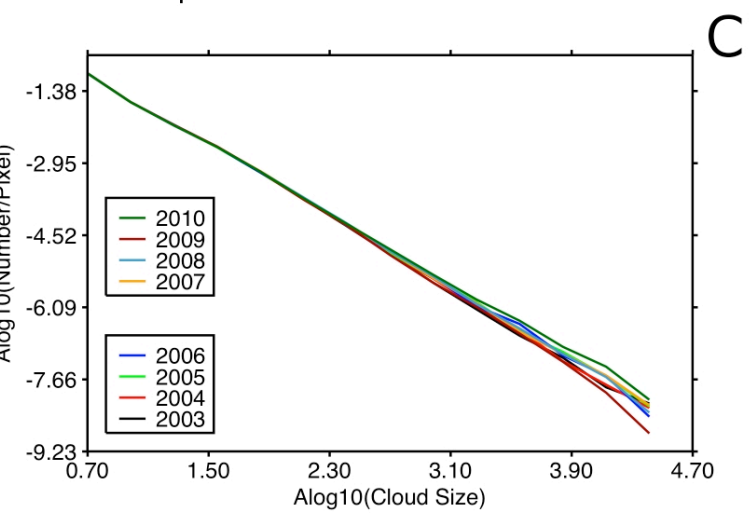

Fig. 1. (A) a MODIS visible image covering roughly the area between $15^{\circ} \mathrm{N}$ and $30^{\circ} \mathrm{N}$ and between $163^{\circ} \mathrm{W}$ and $176^{\circ} \mathrm{W}$. The diversity and complexity of apparent cloud appearance can be appreciated. (B) Cloud size frequency distributions for eight years using Terra data. (C) same as in (B) but using Aqua data. The interannual variation in cloud organization is small. The diurnal variation (Terra versus Aqua) is also small for each year.

of September) (Fig. 3a). It is counter intuitive that the clouds are smaller in the afternoon than those in the morning over land because clouds do generally grow in size from morning to afternoon. We think this contrast is probably due to our sampling: only liquid phased clouds are included, while clouds over land usually grow not only in the horizontal but also in the vertical, making them more likely to be mixed phased or ice phased in the afternoon. Over the trade cumulus region, however, clouds cannot grow in the vertical as much due to capping trade inversion.

\section{A stochastic model}

Large eddy simulation models have demonstrated that simulated small convective cloud sizes (smaller than $1 \mathrm{~km}$ in diameter) follow a power-law distribution (Neggers et al., 2003; Jiang et al., 2009). However, the physical explanation for this cloud behavior is still a scientific challenge (Neggers et al., 2003). Here we introduce a new stochastic complex network model approach to explain the observed cloud self- organization. Using stochastic complex network models to study both fundamental physics (e.g., statistical mechanics and magnetism) and other natural (e.g., cell biology) and social systems (collaborative network) is an active interdisciplinary research area (Albert and Barabasi, 2002; Newman, 2003). These models are usually based on a connected graph that evolves based on a set of rules that mimic the studied system. With the model we want to address the question: what stochastic mechanisms are driving the clouds to organize in the observed fashion?

In this model a cloud, a collection of connected cloudy pixels, is abstracted as a vertex in a graph with the edges connected to the vertex as the cloudy pixels. The degree of a vertex is the number of edges connected to it. It then represents cloud size, and the cloud $P_{k}-K$ relationship is characterized by the degree distribution of a graph (Barabasi and Albert, 1999). To construct and evolve the graph, we note two key physical cloud-organizing processes and represent them with corresponding organizing principles (or rules) in the stochastic complex network model. First we observe 


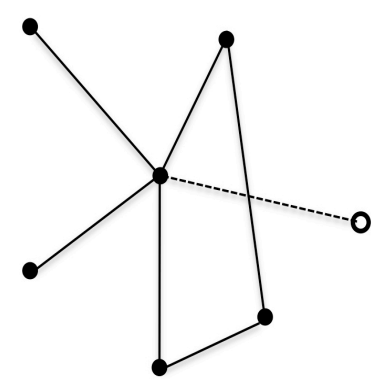

I

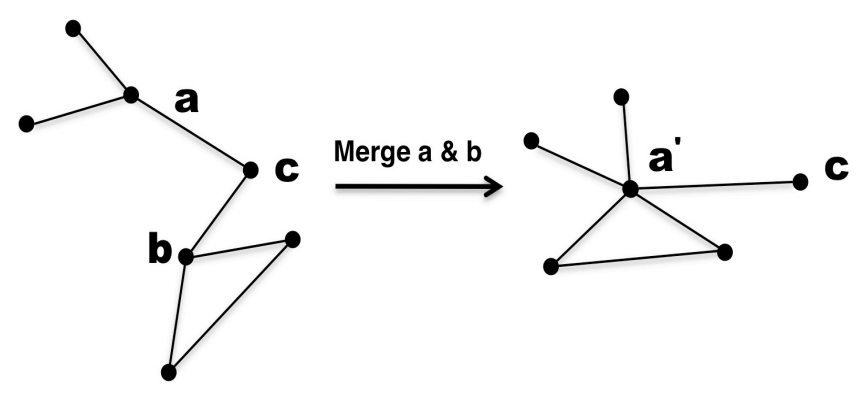

II

Fig. 2. A diagram illustrating the two operations in the model. (I) attachment, where a new vertex is added to the graph and it is connected to an old vertex by an edge; (II) merging, where vertices $\mathrm{a}$ and $\mathrm{b}$ are merged into vertex $\mathrm{a}^{\prime}$; any edge between $\mathrm{a}$ and $\mathrm{b}$ is removed; if $\mathrm{a}$ and $\mathrm{b}$ have a comment neighbor, $\mathrm{c}$ in this case, after the merging only one edge remains between $\mathrm{a}^{\prime}$ and $\mathrm{c}$.

that in nature cloud merging is common (Tao and Simpson, 1984) (Nicholls and LeMone, 1980; Wilcox, 2003), which can be readily appreciated with the naked eye in the afternoon of a summertime fair-weather day. One of the organizing principles for our network model is, thus, two vertices can be randomly selected and merged at $N$ vertices per time interval while vertices are created at $C$ per interval. If the merged vertices are already connected, the edge between them will be removed after merging. Redundant edges between the merged vertices and their common neighbors are also removed, i.e., only one edge will connect the merged vertex and the common neighbors of merged vertices (see Fig. 2). Second, we recognize the observation that clouds often appear in patches over the ocean (Malkus, 1954). It is hypothesized that clouds tend to "clump" together because existing clouds can provide a favorable environment for new cloud formations (Randall and Huffman, 1980). To reflect cloud clumping, our second organizing principle is preferential attachment: when a new vertex is added to the graph, edges will be created at $M$ per time interval to randomly selected vertices. The probability of selecting a vertex $\mathrm{j}$ is proportional to $k_{j} / \sum_{i=1}^{n} k_{i}$, where $k_{i}, k_{j}$ are degrees of vertices $i$ and $j, n$ is the number of vertices in the network at present time. In other words, larger clouds have a better chance of growing.

We start the graph with a few vertices and edges by random assignment, the choice of which does not affect the final outcome of the model. The network grows in size and evolves in its structure based on two organizing principles, merging and clumping, as described above. At each time interval, $C$ new vertices are added to the network and $M$ edges are created for each newly added vertex. The edges are attached to an existing vertex $(j)$ with probability $\Pi$, so that
$\Pi=k_{j} / \sum_{i=1}^{n} k_{i}$. At each time interval $N$ vertices are merged. The set of parameters are therefore $M, N$, and $C$. We can sample the model after it grows sufficiently large (here 4000 vertices are chosen). A degree distribution is shown in Fig. 3 as an example. The degree distribution follows a power law and the exponent $\gamma_{g}$ is around 1.14, comparable to cloud fields over the Caribbean. Our model can effectively reproduce the range of observed $\gamma$ with different combinations of $M, N$, and $C$. We have the following conceptual picture from this model: individual cloud patches and cloudy pixels randomly pop up constantly, the cloud fields organize by randomly merging and clumping, and through these local random interactions macroscopic order (a power law distribution in cloud size) emerges. Here we note a striking analogy between statistical mechanics and cloud organization (or macroscopic behavior of cloud system): macroscopic order emerges based on random, simple microscopic interactions. We propose to adopt a "cloud statistical mechanics" approach to study macroscopic behavior of clouds (Yuan and $\mathrm{Li}, 2010$ ). In this approach individual clouds or cloudy volumes can be treated as the basic elements of the system, and macroscopic cloud behaviors can then be described as the behavior of a system composed of a large number of these basic elements, just like in statistical mechanics where the thermodynamics of a system can be interpreted and explained by statistical behavior of large ensemble of basic elements. The behavior of these elements at its native scales can be measured and studied with traditional instruments and physical deterministic models. The macroscopic behavior of cloud system can then be described using mathematical tools such as probability theory and network theory (as here). The rich and growing arsenal for studying complex networks can provide powerful tools for studying cloud organization with more sophisticated network models. Due 

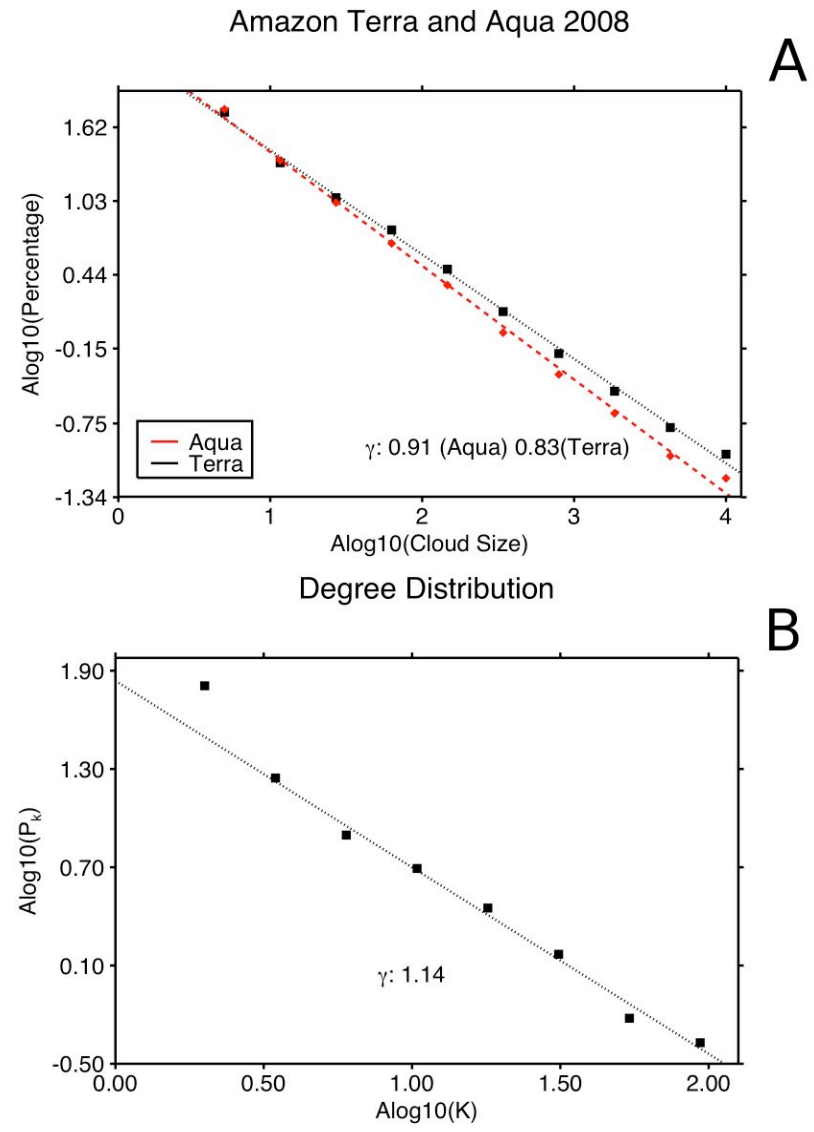

Fig. 3. (A) Cloud size frequency distributions for September 2008 over the clean West Amazon. The two lines are for data from Aqua (in red) and Terra (in black). A more pronounced diurnal variation is noted compared to that over ocean. (B) Degree distributions from the stochastic model run with $M=2, C=3$ and $N=1$. We run the model until it has 4000 vertices. The exponent is close to that observed for trade cumuli over the Caribbean.

to the abstract construct of the model, the approach can be used to understand and study a host of phenomena in climate sciences. A few examples are provided in the following.

Stratocumulus clouds often appear as relatively homogeneous and inter-connected cloud decks. The cloud size distribution for closed cell convection regions does not often obey power law as defined here [SOM]. However, in light of recent fascinating developments on the organization of open cell convection as stratocumulus decks breaking up (Stevens et al., 2005; Xue et al., 2008; Wang and Feingold, 2009; Feingold et al., 2010), we note an intriguing analogy between the organization of trade cumuli and that of clear sky patches inside the open cell stratocumulus region (Fig. 4). First, precipitation is mechanically organizing these open cells of convection by generating mesoscale circulations (Stevens et al., 2005; Xue et al., 2008; Wang and Feingold, 2009; Feingold et al., 2010), and two "clear sky patches" can merge if some clouds at the cell edge randomly disappear due to depleted water or insufficient aerosol. Second, similar to cloud clumping, as a clear sky patch grows in size it is increasingly difficult for new clouds to generate inside them due to the spatial limit of the influence of precipitation outflow and possibly a limiting availability of aerosol particles due to drizzle (Wood et al., 2011). Given these two observations, we postulate that fundamental organizing principles are nearly identical for trade cumuli and clear sky patches inside regions of open cells. Our analysis of clear sky statistics over two regions with frequent appearance of open cell convection (Wood and Hartmann, 2006) confirms this postulation (Fig. 4). The sizes of clear sky cells follow a power law distribution. In other words, there is a striking symmetry between organizations of cloudy and clear skies. However, we argue that this naturally results from the same set of fundamental organizing principles, merging and clumping, when viewed abstractly.

\section{Discussion and summary}

It has been shown that the size distribution has similar scaling behavior for deep convective clouds (Mapes and Houze, 1993; Machado and Rossow, 1993; Wilcox and Ramanathan, 2001; Wilcox, 2003). Noting that cloud merging and clumping are also common for deep convective clouds (Tao and Simpson, 1984; Mapes and Houze, 1993; Wilcox, 2003), we suggest that the macroscopic organization of seemingly completely different forms of convection, shallow versus deep, can be understood with the same organizing principles in a complex network model. Furthermore, precipitation organization shows similar power law behavior (Lovejoy, 1982) and can be considered a direct result of deep convective cloud organization. The moisture organization in the atmosphere may also be understood with the complex network model approach (Kahn and Teixeira, 2009). Robust statistical relationships captured from this approach can also find applications in calculating radiative effect of clouds (Cahalan et al., 1994; Marshak et al., 1994; Barker et al., 1996).

For all potential applications and further development of the complex network models, observations and physical understanding of key processes that determine the final structure of a system are required. For example, merging rates and clumping rates (growth rate for different cloud sizes) of clouds may be observed from satellite data (Wilcox, 2003) or physical cloud resolving models (Jiang et al., 2009). These observations can be used to constrain the network model parameters and validate network model outputs. Furthermore, different mechanisms of cloud merging (e.g., cold pool, dynamical waves) may be represented in a more advanced network model, and dynamic interactions among and relative importance of these mechanisms may be investigated.

All observed power law exponents for cloud size distributions in this study are close to 2, which is somewhat larger than that of Kolmogorov exponent of $5 / 3$ in a homogeneous and steady turbulence regime. Assuming that observations 

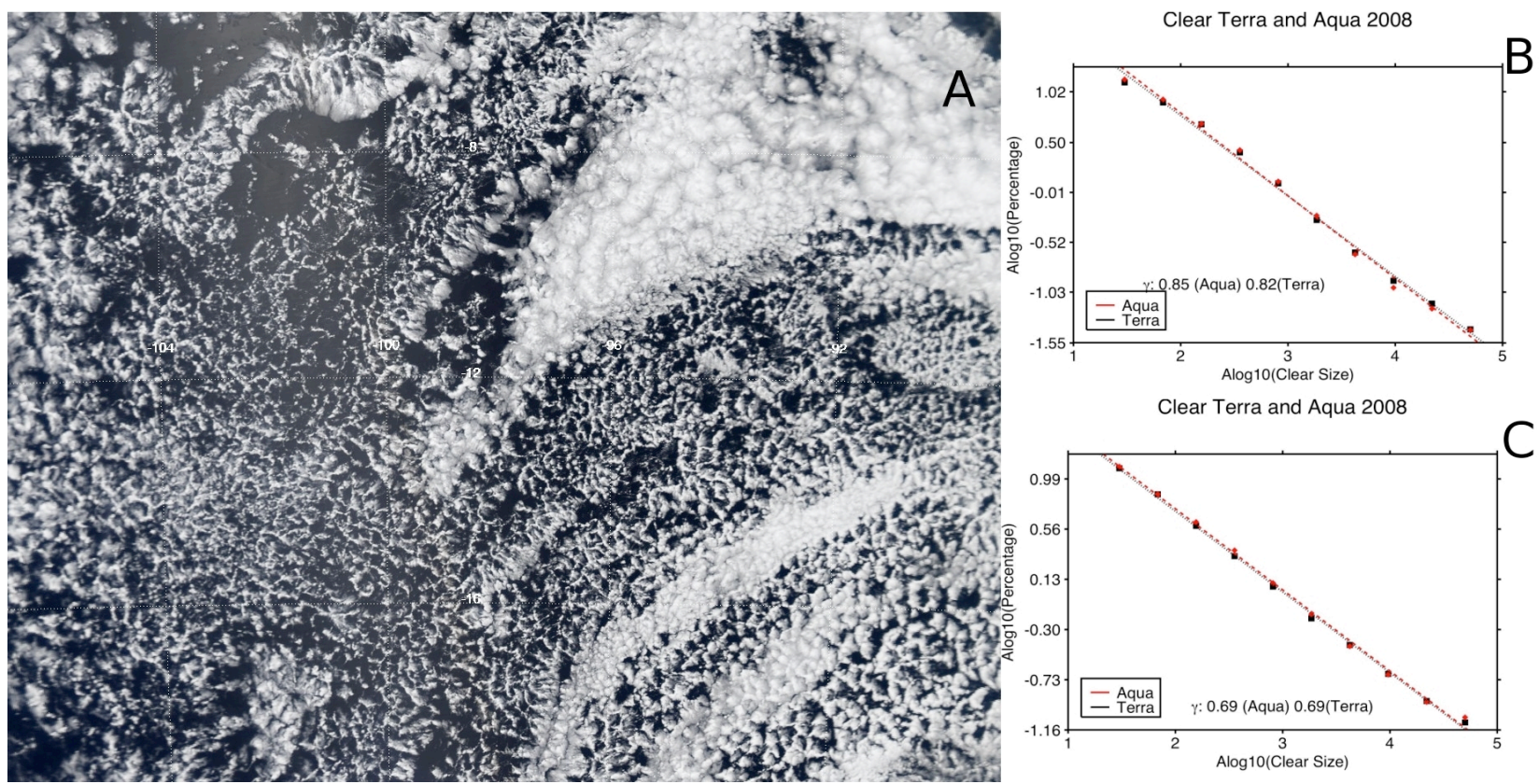

Fig. 4. (A) A visible MODIS image showing a stratocumulus deck breaking up. Open cell convections dominate the scene. It is over the Southern Pacific. (B) Clear sky size distributions for September 2008 over the South Pacific open cell region (Wood and Hartmann, 2006). Both Aqua and Terra data are shown. (C) same as (B) but for open cell clouds over North Pacific (Wood and Hartmann, 2006).

here and those reported in previous studies are representative of the true value, this implies that the effect of phase change and inhomogeneity in thermodynamic properties of the real atmosphere has a significant impact on the distribution of energy across the spectrum of turbulent eddy sizes. The larger than $5 / 3$ exponent implies the suppression of larger eddy formations compared to homogeneous turbulence regime. This suppression effect could be a result of a few factors such as entrainment of free troposphere air mass, latent heat of phase transition, radiative cooling/heating, and air-surface energy exchange. The geographic variation of the exponent reported in this study and in the literature should therefore be a result of the thermodynamic differences in air masses under contrasting climate regimes. Nevertheless, the conceptual understanding of the scaling behavior is similar to the organization of Kolmogorov vortices: bigger vortices (or clouds) are made from smaller ones, and the way it is made is the same throughout the range of scales observed here and in previous studies. This conceptual view fits quite nicely with the organization principles of the complex network model proposed here since these principles are not sensitive to individual cloud (or vortex) size at all.

It is important to note that the cloud statistical mechanics approach and deterministic cloud models are fully complementary to each other. On one hand, observations on the behavior of cloud macroscopic properties can provide insights for deterministic models to determine microscopic processes that are responsible. For example, while our stochastic model can effectively produce the regional variation of $\gamma$, the actual clumping and merging rates (or other factors that contribute to different cloud organization) should come from observations or deterministic model simulations with detailed microphysical processes (Siebesma and Jonker, 2000; Neggers et al., 2003). On the other hand, insights on microscopic processes can in turn improve the construct of stochastic models. An example is the issue of aerosol-cloud interactions. Recent simulations suggest increased aerosol concentration leads to stronger evaporation at cloud sides, which results in more but smaller clouds (all are smaller than $1 \mathrm{~km}$ ) (Jiang et al., 2009). This microscopic influence of aerosols would be expected to change cloud macroscopic organization since it can modify cloud merging and clumping rates. The interplay between these two approaches has a great potential to pinpoint processes that are most critical for cloud macroscopic properties and to faithfully model these properties using computationally cheap stochastic models. The statistical mechanics approach thus provides a framework that translates knowledge from micro-scale (cloud or convective cell) processes to cloud macro-scale properties, which provides a viable venue to meet the need of climate models to represent statistical cloud macro-scale properties.

In summary, we show a self-organization of warm cumulus clouds at spatial scales ranging across four orders of magnitude in horizontal scale under a relatively homogeneous environment. A novel stochastic model constructed on a graph can effectively capture the essential cloud organization 
behavior and its regional variations. We demonstrate that clear sky organization in a broken stratocumulus field has the same behavior because, we argue, similar underlying organizing principles exist. Studying cloud statistical mechanics on complex networks in tandem with deterministic cloud models could potentially provide a powerful framework for advancing our understanding of clouds.

\section{Supplementary material related to this article is available online at: http://www.atmos-chem-phys.net/11/7483/2011/ acp-11-7483-2011-supplement.pdf.}

Acknowledgements. I thank Eric Wilcox and the other anonymous reviewer as well as the editor Timothy Garrett for their constructive and helpful comments. Discussions with Lazaros Oreopoulos and Lorraine Remer are also helpful. Funding is provided by NASA IDS and Radiation Science programs.

Edited by: T. Garrett

\section{References}

Albert, R. and Barabasi, A. L., Statistical mechanics of complex networks, Rev Mod Phys, 74(1), 47-97, 2002.

Barabasi, A. L. and Albert, R.: Emergence of scaling in random networks. Science, 286, 5439, 509-512, 1999.

Barker, H. W., Wielicki, B. A., and Parker, L.: A parameterization for computing grid-averaged solar fluxes for inhomogeneous marine boundary layer clouds.2. Validation using satellite data, J. Atmos. Sci., 53(16), 2304-2316, 1996.

Benner, T. C. and Curry, J. A.: Characteristics of small tropical cumulus clouds and their impact on the environment, J. Geophys. Res.-Atmos., 103(D22), 28753-28767, 1998.

Bony, S., Colman, R., Kattsov, V. M., Allan, R. P., Bretherton, C. S., Dufresne, J., Hall, A., Hallegatte, S., Holland, M. M., Ingram, W., Randall, D. A., Soden, B. J., Tselioudis, G., and Webb, M. J.: How well do we understand and evaluate climate change feedback processes?, J. Climate, 19(15), 3445-3482, 2006.

Cahalan, R. F. and Joseph, J. H.: Fractal statistics of cloud fields, Mon. Weather Rev., 117(2), 261-272, 1989.

Cahalan, R. F., Ridgway, W., Wiscombe, W. J., Bell, T. L., and Snider, J. B.: The albedo of fractal stratocumulus clouds, J. Atmos. Sci., 51(16), 2434-2455, 1994.

Feingold, G., Koren, I., Wang, H., Xue, H., and Brewer, W. A.: Precipitation-generated oscillations in open cellular cloud fields. Nature, 466(7308), 849-852, doi:10.1038/nature09314, 2010.

Hartmann, D. L. and Doelling, D.: On the net radiative effectiveness of cloudss, J. Geophys. Res.-Atmos.,96(D1), 869-891, 1991.

Jiang, H., Feingold, G., and Koren, I.: Effect of aerosol on trade cumulus cloud morphology, J. Geophys. Res.-Atmos., 114, D11209, doi:10.1029/2009JD011750, 2009.

Kahn, B. H. and Teixeira, J.: A Global Climatology of Temperature and Water Vapor Variance Scaling from the Atmospheric Infrared Sounder, J Climate, 22(20), 5558-5576, doi:10.1175/2009JCLI2934.1, 2009.
Klein, S. A. and Hartmann, D. L.: The seasonal cycle of low stratiform clouds, J Climate, 6(8), 1587-1606, 1993.

Koren, I., Oreopoulos, L., Feingold, G., Remer, L. A., and Altaratz, O.: How small is a small cloud?, Atmos. Chem. Phys., 8, 38553864, doi:10.5194/acp-8-3855-2008, 2008.

Kuo, K. S., Welch, R. M., Weger, R. C., Engelstad, M. A., and Sengupta, S. K.: The 3-dimensional structure of cumulus clouds over the ocean.1. structural-analysis, J. Geophys. Res.-Atmos., 98(D11), 20685-20711, 1993.

Lovejoy, S.: Area-perimeter relation for rain and cloud areas, Science, 216(4542), 185-187, 1982.

Machado, L. A. T. and Rossow, W. B.: Structural characteristics and radiative properties of tropical cloud clusters, Mon. Weather Rev., 121(12), 3234-3260, 1993.

Malkus, J. S.: Some results of a trade-cumulus cloud investigation, J. Meteorol., 11(3), 220-237, 1954.

Mapes, B. E. and Houze, R. A.: Cloud clusters and superclusters over the oceanic warm pool, Mon. Weather Rev., 121(5), 13981415, 1993.

Marshak, A., Davis, A., Cahalan, R., and Wiscombe, W.: Bounded cascade models as nonstationary multifractals, Phys. Rev. E, 49(1), 55-69, 1994.

Neggers, R. A. J., Jonker, H. J. J., and Siebesma, A. P.: Size statistics of cumulus cloud populations in large-eddy simulations, J. Atmos. Sci., 60(8), 1060-1074, 2003.

Newman, M. E. J.: The structure and function of complex networks, Siam. Rev., 45(2), 167-256, 2003.

Nicholls, S. and Lemone, M. A.: The fair weather boundary layer in GATE - the relationship of sub-cloud fluxes and structure to the distribution and enhancement of cumulus clouds, J. Atmos. Sci., 37(9), 2051-2067, 1980.

Platnick, S., King, M. D., Ackerman, S. A., Menzel, W. P., Baum, B. A., Riedi, J. C., and Frey, R. A.: The MODIS cloud products: Algorithms and examples from Terra, IEEE T. Geosci. Remote Sens., 41(2), 459-473, doi:10.1109/TGRS.2002.808301, 2003.

Ramanathan, V., Cess, R. D., Harrison, E. F., Minnis, P., Barkstrom, B. R., Ahmad, E., and Hartmann, D.: Cloud-Radiative forcing and climate- results from the Earth Radiation Budget Experiment, Science, 243(4887), 57-63, 1989.

Randall, D. A. and Huffman, G. J.: A stochastic-model of cumulus clumping, J. Atmos. Sci., 37(9), 2068-2078, 1980.

Siebesma, A. P. and Jonker, H. J. J.: Anomalous scaling of cumulus cloud boundaries, Phys. Rev. Lett., 85(1), 214-217, 2000.

Stevens, B.: Atmospheric moist convection, Annu. Rev. Earth Pl. Sc., 33, 605-643, doi:10.1146/annurev.earth.33.092203.122658, 2005.

Stevens, B. and Feingold, G.: Untangling aerosol effects on clouds and precipitation in a buffered system, Nature, 461(7264), 607613, doi:10.1038/nature08281, 2009.

Stevens, B., Vali, G., Comstock, K., Wood, R., Van Zanten, M. C., Austin, P. H., Bretherton, C. S., and Lenschow, D. H.: Pockets of open cells and drizzle in marine stratocumulus, B. Am. Meteorol. Soc., 86(1), 51-57, doi:10.1175/BAMS-86-1-51, 2005.

Tao, W. K. and Simpson, J.: Cloud interactions and merging- numerical simulations, J. Atmos. Sci., 41(19), 2901-2917, 1984.

Wang, H. and Feingold, G.: Modeling Mesoscale Cellular Structures and Drizzle in Marine Stratocumulus. Part I: Impact of Drizzle on the Formation and Evolution of Open Cells, J. Atmos. Sci., 66(11), 3237-3256, doi:10.1175/2009JAS3022.1, 2009. 
Wielicki, B. A. and Welch, R. M.: CUMULUS CLOUD PROPERTIES DERIVED USING LANDSAT SATELLITE DATA, J. Clim. Appl. Meteorol., 25(3), 261-276, 1986.

Wilcox, E.: Spatial and temporal scales of precipitating tropical cloud systems in satellite imagery and the NCAR CCM3, J. Climate, 16(22), 3545-3559, 2003.

Wilcox, E. M. and Ramanathan, V.: Scale dependence of the thermodynamic forcing of tropical monsoon clouds: Results from TRMM observations, J. Climate, 14(7), 1511-1524, 2001.

Wood, R. and Hartmann, D. L.: Spatial variability of liquid water path in marine low cloud: The importance of mesoscale cellular convection, J. Climate, 19(9), 1748-1764, 2006.

Wood, R., Bretherton, C. S., Leon, D., Clarke, A. D., Zuidema, P., Allen, G., and Coe, H.: An aircraft case study of the spatial transition from closed to open mesoscale cellular convection over the Southeast Pacific, Atmos. Chem. Phys., 11, 2341-2370, doi:10.5194/acp-11-2341-2011, 2011.
Xue, H., Feingold, G., and Stevens, B.: Aerosol effects on clouds, precipitation, and the organization of shallow cumulus convection, J. Atmos. Sci., 65(2), 392-406, doi:10.1175/2007JAS2428.1, 2008.

Yuan, T. and Li, Z.: General Macro- and Microphysical Properties of Deep Convective Clouds as Observed by MODIS, J. Climate, 23(13), 3457-3473, doi:10.1175/2009JCLI3136.1, 2010.

Zhao, G. and Di Girolamo, L.: Statistics on the macrophysical properties of trade wind cumuli over the tropical western Atlantic, J. Geophys. Res.-Atmos., 112(D10), D10204, doi:10.1029/2006JD007371, 2007. 